\title{
Traf4 is required for tight junction complex during mouse blastocyst formation
}

\author{
Jian Lee ${ }^{1,2}$ and Inchul Choi ${ }^{2, *}$ \\ ${ }^{1}$ Dairy Science Division, National Institute of Animal Science, RDA, Cheonan 31000, Korea \\ ${ }^{2}$ Division of Animal and Dairy Sciences, College of Agriculture and Life Sciences, Chungnam National University, \\ Daejeon 34134, Korea
}

Received October 25, 2021

Revised November 17, 2021

Accepted November 18, 2021

*Correspondence

Inchul Choi

E-mail: icchoi@cnu.ac.kr

Author's Position and Orcid no. Lee J, Researcher,

https://orcid.org/0000-0002-1774-4167

Choi I, Associate professor,

https://orcid.org/0000-0001-5011-2658

\begin{abstract}
Traf4 (Tumor necrosis factor Receptor Associated Factor 4) is a member of the tumor necrosis factor receptor (TNFR) - associated factors (TRAFs) family. TRAF4 is overexpressed in tumor cells such as breast cancer and associated with cytoskeleton and membrane fraction. Interestingly, TRAF4 was localized with tight junctions (TJs) proteins including OCLN and TJP1 in mammary epithelial cells. However, the expression patterns and biological function of Traf4 were not examined in preimplantation mouse embryos although Traf4-deficient mouse showed embryonic lethality or various dramatic malformation. In this study, we examined the temporal and spatial expression patterns of mouse Traf4 during preimplantation development by qRT-PCR and immunostaining, and its biological function by using siRNA injection. We found upregulation of Traf4 from the 8-cell stage onwards and apical region of cell - cell contact sites at morula and blastocyst embryos. Moreover, Traf4 knockdown led to defective TJs without alteration of genes associated with $\mathrm{TJ}$ assembly but elevated $\mathrm{p} 21$ expression at the KD morula. Taken together, Traf4 is required for TJs assembly and cell proliferation during morula to blastocyst transition.
\end{abstract}

Keywords: blastocyst, preimplantation, p21, tight junction, Traf4

\section{INTRODUCTION}

A fertilized one-cell zygote undergoes a series of cleavage divisions and a process known as compaction to become a morula. The compacted morula eventually develops into a blastocyst, a distinct mammalian embryo stage during the preimplantation period. This morphogenetic transition is observed in early stage mouse embryos, for example via activation of paracellular adhesion and cellular polarization at the 8-cell stage (Kidder and McLachlin, 1985; Tesarík, 1988; Zhou et al., 2020). Subsequently, external blastomeres start to take up fluid from the uterus and pump it centrally, creating the blastocoel via tight junction (TJ) assembly or biogenesis (Watson and Barcroft, 2001). Finally, the external blastomeres differentiate into the trophectoderm (TE) and the internal cells develop into the inner cell mass (ICM). The TE and ICM contribute to establishment of the placenta and fetus, respectively (Cockburn and Rossant, 2010).

Tumor necrosis factor receptor associated factor 4 (Traf4) belongs to the tumor necrosis factor receptorassociated factor (TRAF) family, which is found in the cell membrane and cytoplasm (Régnier et al., 1995; Kedinger and Rio, 2007). TRAF4 is overexpressed in breast cancer, and exists in the cytoskeleton and membrane fractions in other cancers (Xu et al., 2002; Camilleri-Broët et al., 
2007). In epithelial cells, TRAF4 is localized with TJ markers such as OCLN and TJP1 (also known as ZO-1) in the apical regions of cell-cell boundaries, and affects the stability of apical cell-cell junctions in mammary epithelial cells (Kédinger et al., 2008; Rousseau et al., 2011; Park and Kim, 2019). The Traf4-deficient mouse shows approximately $30 \%$ embryonic lethality, and causes various changes and dramatic malformations in the trachea and axial skeleton (Régnier et al., 2002). However, the expression patterns and biological function of Traf 4 have not been examined in preimplantation mouse embryos.

In this study, we investigated the expression and localization of Traf 4 during preimplantation development, and its biological functions, by injecting 1-cell zygotes with siRNA.

\section{MATERIALS AND METHODS}

All the animal studies were approved by Institution Animal Care and Use Committee guidelines from the Chungnam National University Animal Welfare and Ethical Review Body (License No. CNU-00702), and all chemicals, unless otherwise stated, were purchased from SigmaAldrich (St. Louis, MO, USA).

\section{Embryo collection and microinjection}

As previously described (Jeong and Choi, 2019), five female mice (6-8 week-old C57 BL/6; KOATECH, Pyeongtaek, Republic of Korea) were superovulated by injecting 5 IU of pregnant mare's serum gonadotropin (PMSG) followed by 5 IU human chorionic gonadotropin (hCG) 48 hours later for one biological experiment. Immediately, female mice were mated with $\mathrm{B} 6 / \mathrm{n}$ males (10-24 week- old; KOATECH) after injection of hCG. Fertilized one-cell zygotes were collected in M2 medium at 16-18 hours post hCG (hph) injection from ampulla of the mouse oviducts and then cultured in M16 medium including 0.003\% EDTA, $0.06 \%$ penicilin $G$ postassuim salt, $0.005 \%$ streptomycin sulfate under mineral oil at $37^{\circ} \mathrm{C}$ in a humidified atmosphere of $5 \% \mathrm{O} 2,5 \% \mathrm{CO}_{2}, 90 \% \mathrm{~N}_{2}$. For knock down (KD) experiments, $5-10 \mathrm{pl}$ of $100 \mu \mathrm{M}$ TRAF4 siRNA (siGenome; Dharmacon, CO, USA), or $100 \mu \mathrm{M}$ control non-target siRNA (Dharmarcon) was injected into the cytoplasm of onecell zygote embryos using microinjector at 19-21 hph, and the injected embryos were cultured for four days. Traf 4 KD ( $n=203)$, and control ( $n=193)$ embryos were used for developmental analysis.

\section{Real-time quantitative PCR}

Total RNA was isolated from groups of at least ten embryos using the PicoPure RNA isolation kit (Arcturus, Mountain View, CA, USA) and cDNA was synthesized by using Superscript II reverse transcriptase (Invitrogen, Carlsbad, CA, USA). Real-time qPCR analysis was performed on a StepOnePlus real-time PCR system (Applied Biosystems, Foster, CA, USA) using gene-specific designed primers (Table 1). Ubtf and GFP was used as endogenous and exogenous controls for KD and preimplantation development stage, respectively. For gene expression analysis, 60 control and 60 Traf4 KD morula embryos were used (10 embryos per biological replication and 6 times repeated).

\section{Immunocytochemistry}

Preimplantation embryos were fixed with $3.7 \%$ paraformaldehyde for 20 minutes, permeabilized with phosphate-

Table 1. Primers sequences for qRT-PCR

\begin{tabular}{|c|c|c|}
\hline Gene & Forward sequences $\left(5^{\prime}-3^{\prime}\right)$ & Reverse sequences (5'-3') \\
\hline Traf4 & TGCCAGCCACATTCTACCTG & ТАССТСССАСССССАСТАТG \\
\hline Tjp1 & TTTGGGCTGTGCATCTGA & TGCTTTATTGCTGCAGAGG \\
\hline Ocln & ACGTCGTGGACCGGTATC & AAAAACAGTGGTGGGGAAC \\
\hline Adam 10 & ССTGCCATTTCACTCTGTCA & GGGCTCCTTCCTCTACTCCA \\
\hline p21 & GCAGATCCACAGCGATATCC & СAACTGCTCACTGTCCACGG \\
\hline p53 & GGGGAGGAGCCAGGCCATCA & CCGCGCCATGGCCATCTACA \\
\hline Rock1 & ACCCACCATCTGGCTTTGTC & CGGTTTATCAGGTAGCATCCC \\
\hline Rock2 & GATGGTTGTCATTGCCTGTGC & TGCTCTTTATCTTGTTCGCTGT \\
\hline Ubtf & CGCGCAGCATACAAAGAATACA & GTTTGGGCCTCGGAGCTT \\
\hline GFP & AAGCTGACCCTGAAGTTCATCTGC & CTTGTAGTTGCCGTCGTCCTTGAA \\
\hline
\end{tabular}


buffered saline (PBS) containing 0.1\% Tween 20 for 20 minutes, blocked with PBS containing $0.1 \%$ bovine serum albumin (BSA) for 1 hour at room temperature, and incubated with a primary antibody, Traf4 (C-20; Santa Cruz Biotechnology, Santa Cruz, CA, USA), or Tjp1 (also known as ZO-1, 40-2200; Invitrogen) overnight in blocking solution at $4^{\circ} \mathrm{C}$. For detection, the treated embryos were incubated with AlexaFluor488- or 594-labelled secondary antibody (Molecular Probes, Eugene, OR, USA) for $30 \mathrm{~min}$ at room temperature, and then mounted in Vectashield containing 4,6-diamidino-2-phenylindole (DAPI) (Vector Laboratories, Burlingame, CA, USA). Images were captured using a laser scanning confocal microscope (C2puls; Nikon, Tokyo, Japan) and processed with NIS-Elements software (Nikon).

\section{FITC-dextran uptake assay}

52 control (17-36/assay) and $79 \mathrm{KD}$ blastocyst (16-20/ assay) were incubated in M16 medium containing $4 \mathrm{kDa}$ FITC-dextran $(1 \mathrm{mg} / \mathrm{mL})$ for $10 \mathrm{~min}$ at $37^{\circ} \mathrm{C}$ and then washed in fresh M2 medium three four times. Diffusion of FITC-dextran into the blastocoel was examined in a clean drop of M2 medium by an inverted fluorescence microscope (Nikon Eclipse Ti-U, Nikon).

\section{Statistical analysis}

Data were analyzed by analysis of variance (ANOVA) using GraphPad Prism (Version 5.03, GraphPad Software, San Diego, CA, USA), and are presented as mean \pm s.e.m. (Standard error mean). $p$ values $<0.05$ were considered statistically significant differences unless otherwise stated.

\section{RESULTS AND DISCUSSION}

We previously identified several genes involved in tight junctions of blastocyst such as Tfap2c, Cxadr, Adam 10, and Rock in pig and mouse embryos and reported that TJ biogenesis and assembly is conserved across mammalian embryos (Kwon et al., 2016a; Kwon et al., 2016b; Kwon et al., 2016c; Jeong et al., 2019). Here we reported that expression patterns of Traf 4 and its biological function in terms of tight junction assembly during morula to blastocyst transition.

\section{Expression of TRAF4 in mouse preimplantation embryos}

To assess the expression of Traf 4 during mouse preimplantation development, we examined transcript levels using qRT-PCR and ICC. Traf4 transcripts were detected at all preimplantation embryo stages, although the expression gradually decreased until the 4-cell stage. However, the zygotic expression of Traf 4 transcripts increased from the 8-cell stage onwards (Fig. 1A). Traf4 proteins were observed in the cytoplasm of early cleaving embryos, and were more densely located in cell-cell contact sites. Apical localization was detected from the 4-cell stage and was more obvious in the morula and blastocyst (Fig. 1B). Moreover, ICC assay showed that Traf4 and Tjp1 colocalized in the apical regions of outer cells (Fig. 1B).

\section{Effects of Traf4 KD on preimplantation embryo development}

To abolish maternally derived and zygotic Traf4 mRNA during early embryo development, Traf 4 siRNA $(100 \mu \mathrm{M})$ was injected into 1-cell zygote embryos. The knockdown (KD) efficiency was measured using qRT-PCR, which showed that Traf4 mRNA was successfully depleted (by > $80 \%$ in the morula).

We observed significant differences in blastocyst development between control $(81.5 \pm 3.0 \%)$ and Traf4 KD (49.2 $\pm 4.7 \%$ ) embryos (Fig. 2A and 2B). Interestingly, we also observed collapsed blastocyst cavities in the KD embryos (Fig. 2A), suggesting that the loss of Traf4 affects TJ assembly during the morula to blastocyst transition.

Next, to determine whether the deletion of Traf 4 causes defective TJs in blastocysts, blastocoel diffusion assay was performed using FITC-dextran uptake to assess cell-cell barrier function (Choi et al., 2012). There were significant differences in TJ permeability (FITC-positive signals) between the control $(19.9 \pm 4.7 \%)$ and Traf4 KD $(43.4 \pm 4.7$ \%) embryos (Fig. 2C and 2D), suggesting that Traf4 localized to apical regions is involved in intercellular sealing via $\mathrm{TJ}$ assembly rather than $\mathrm{AJs}$.

\section{Effects of Traf4 KD on the gene expression associated with TJs and the cell cycle}

In agreement with previous $\mathrm{TJ}$ assembly studies in mouse and pig embryos (Choi et al., 2012; Kwon et al., 2016a; Kwon et al., 2016c; Jeong et al., 2019; Kwon et al., 2019), we attributed defective paracellular sealing in 

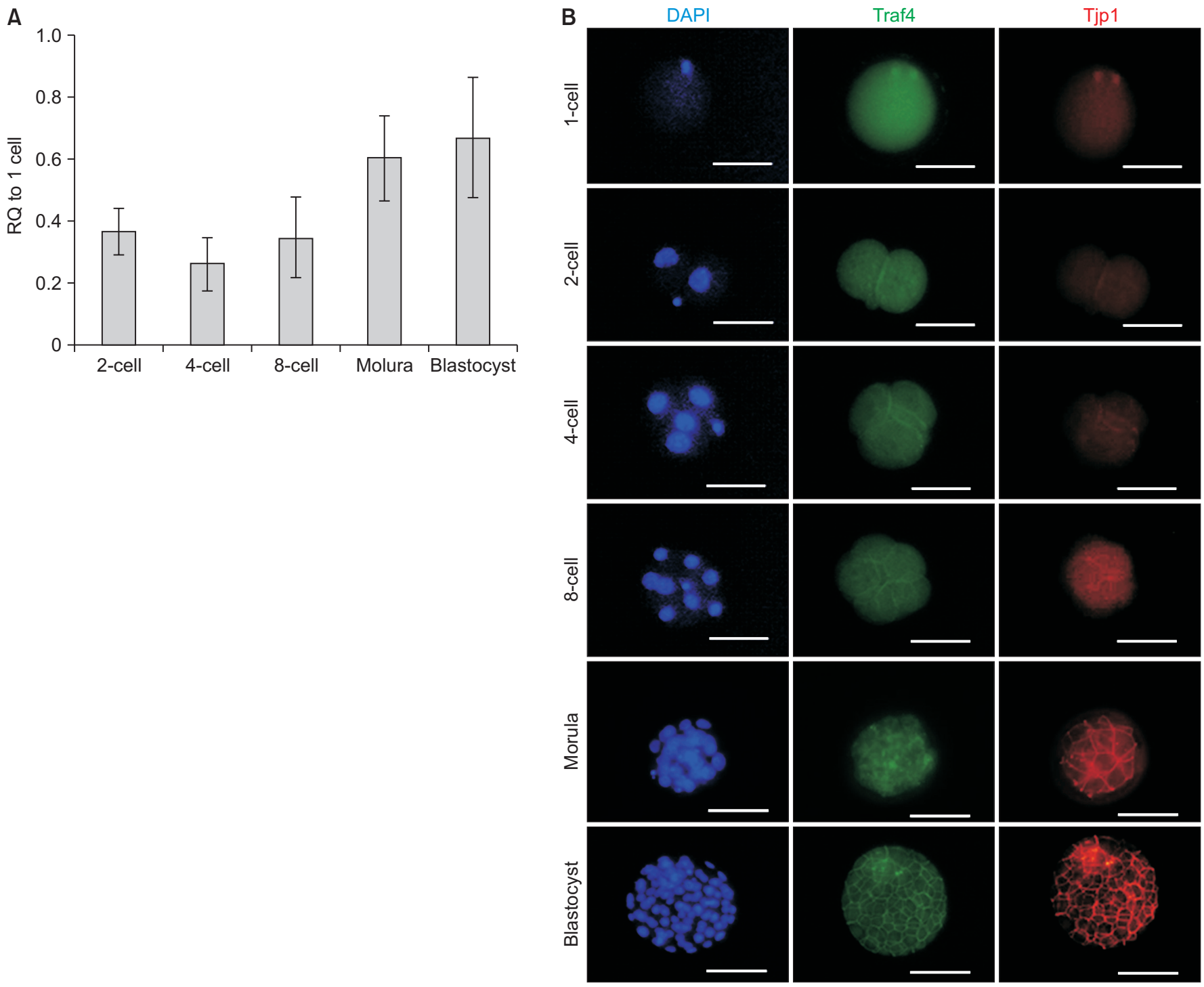

Fig. 1. Expression patterns of Traf4 during mouse preimplantation development. (A) Transcription levels of Traf4 were measured from the 1 cell to blastocyst stages using qRT-PCR. Expression levels were normalized to an exogenous control gene (Gfp). (B) Cellular localization of Traf4 were analyzed by immunocytochemistry. Scale bar (50 $\mu \mathrm{m})$. Error bars represent mean \pm standard error.

Traf4 KD blastocysts to the altered gene expression and protein localization required for establishing TJs, or to abnormal cell cycle checkpoint gene expression during cell proliferation. We examined the expression of the TJ genes Tjp1, Ocln, Adam10, Rock1, and Rock2 (Kwon et al., 2016b; Jeong et al., 2019), and the cell proliferation genes p21 (also known as Cdkn1a) and p53 (also known as Trp53), in morula embryos using qRT PCR (Hoeferlin et al., 2011; Muñoz-Espín et al., 2013; Ock et al., 2020).

The expression of genes associated with TJ biogenesis was not changed in the Traf $4 \mathrm{KD}$ embryos. However, the KD morula embryos showed increased p21 expres- sion compared with control embryos (Fig. 3). In line with previous reports of the upregulation of $p 21$ transcripts in mouse embryos associated with embryonic arrest during the morula to blastocyst transition (Choi et al., 2012; Ock et al., 2020), the retarded development of morula embryos might be attributed to the elevated p21 expression. Although we did not find direct evidences for an inverse relationship between Traf4 and p53-p21 signaling activity (Rozan and El-Deiry, 2006; Deng et al., 2019), Traf4 suppression might affect cell proliferation in preimplantation embryos via the p21 pathway. 

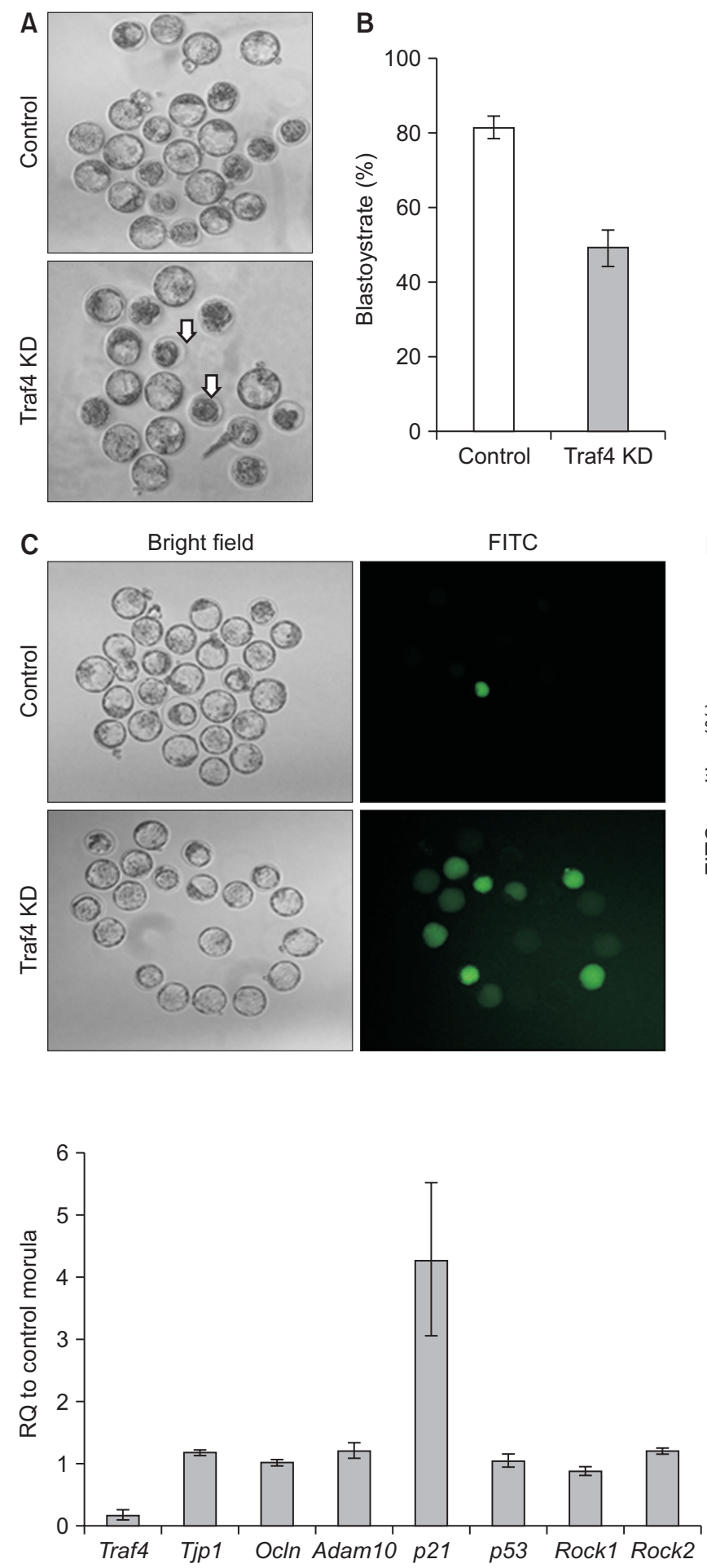

Fig. 3. Gene expression patterns of Tfa4 KD embryos. In the Traf4 KD morula, expression levels of TJs and cell cycle associated genes were not changed except for $\mathrm{p} 21$. RQ (Relative Quantification). Error bars represent mean \pm standard error.
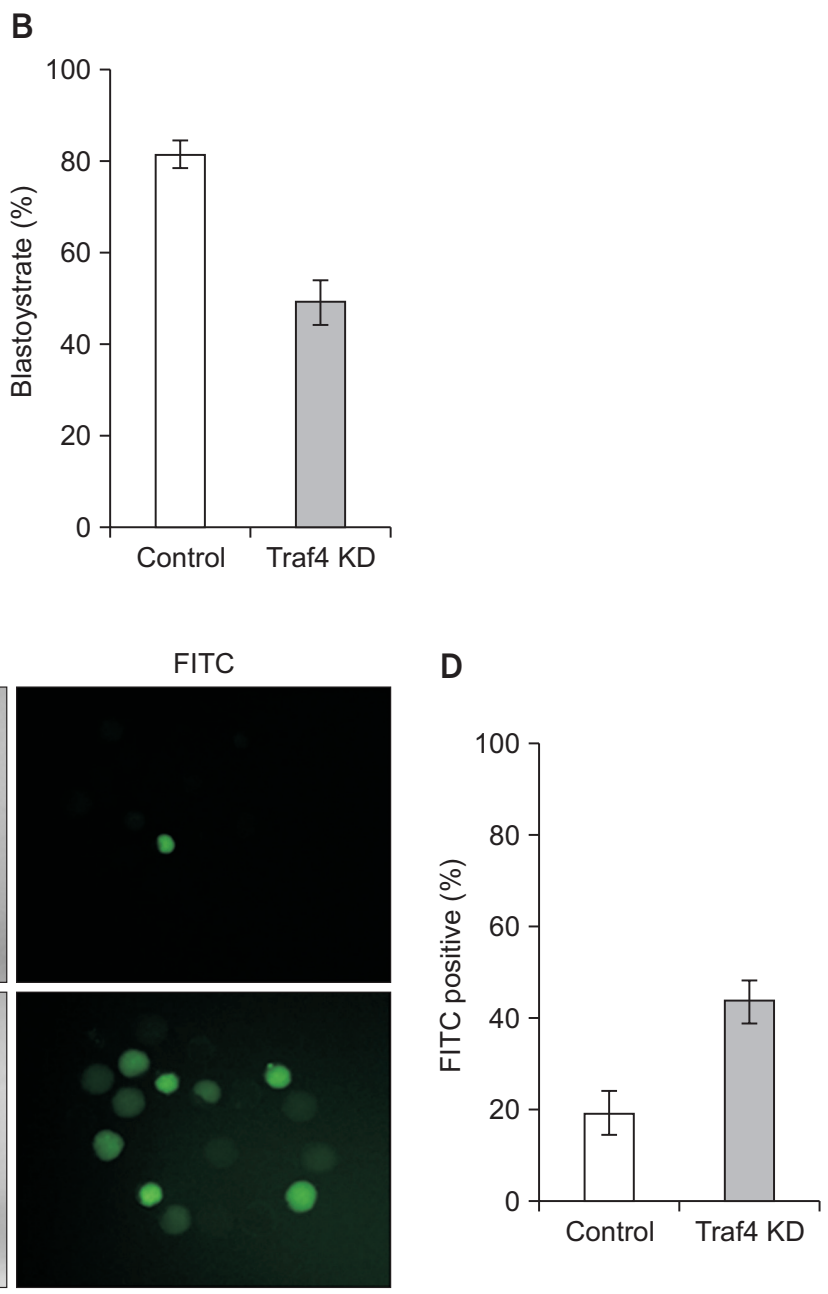

Fig. 2. Effects of Traf4 KD on embryos. (A) Representative images of blastocyst development at $120 \mathrm{~h}$ after hCG. (B) Blastocyst development rate. (C) Representative images of defective paracellular sealing in Traf4 KD blastocysts. (D) 4kDa FITC-dextran uptake assay was used for TJs permeability. White arrows indicate collapsed blastocoel.

\section{CONCLUSION}

This study examined the spatiotemporal expression of mouse Traf4 during preimplantation development, and investigated its function using RNAi. The upregulation from the 8-cell stage onwards, apical localization, and loss of function study indicates that Traf4 is required for blastocyst development rather than morula compaction. The permeability assay confirmed the need for Traf4 for TJ assembly, and elevated p21 expression was associated with embryonic arrest at the morula stage in the KD embryos. Moreover, it is critical to evaluate and select developmentally competent embryos during preimplantation stage because the embryos produced by in vitro system (in vitro maturation, fertilization and culture) show lower blastocyst development and fail to implant. 
Author Contributions: Conceptualization, I.C.; methodology, I.C. and J.L.; Investigation, J.L.; data curation, I.C. and J.L.; writing-original draft preparation, J.L.; writing-review and editing, I.C.; supervision, I.C.; project administration, I.C.; funding acquisition, I.C.

Funding: This study was supported by Chungnam National University.

Ethical Approval: Not applicable.

Consent to Participate: Not applicable.

Consent to Publish: Not applicable.

Availability of Data and Materials: Not applicable.

\section{Acknowledgements: None.}

Conflicts of Interest: No potential conflict of interest relevant to this article was reported.

\section{REFERENCES}

Camilleri-Broët S, Cremer I, Marmey B, Comperat E, Viguié F, Audouin J, Rio MC, Fridman WH, Sautès-Fridman C, Régnier CH. 2007. TRAF4 overexpression is a common characteristic of human carcinomas. Oncogene 26:142-147.

Choi I, Carey TS, Wilson CA, Knott JG. 2012. Transcription factor AP- $2 \gamma$ is a core regulator of tight junction biogenesis and cavity formation during mouse early embryogenesis. Development 139:4623-4632.

Cockburn K and Rossant J. 2010. Making the blastocyst: lessons from the mouse. J. Clin. Invest. 120:995-1003.

Deng CC, Zhu DH, Chen YJ, Huang TY, Peng Y, Liu SY, Lu P, Xue YH, Xu YP, Yang B, Rong Z. 2019. TRAF4 promotes fibroblast proliferation in keloids by destabilizing p53 via interacting with the deubiquitinase USP10. J. Invest. Dermatol. 139:1925-1935.e5.

Hoeferlin LA, Oleinik NV, Krupenko NI, Krupenko SA. 2011. Activation of p21-dependent G1/G2 arrest in the absence of DNA damage as an antiapoptotic response to metabolic stress. Genes Cancer 2:889-899.

Jeong Y and Choi I. 2019. Tight junction assembly ensures maintenance of pregnancy during embryogenesis in a mouse model. J. Anim. Reprod. Biotechnol. 34:318-321.

Jeong Y, Ock SA, Yoo JG, Yu DY, Choi I. 2019. The Cxadr-Adam10 complex plays pivotal roles in tight junction integrity and early trophoblast development in mice. Mol. Reprod. Dev. 86:1628-1638.
Kédinger V, Alpy F, Baguet A, Polette M, Stoll I, Chenard MP, Tomasetto C, Rio MC. 2008. Tumor necrosis factor receptorassociated factor 4 is a dynamic tight junction-related shuttle protein involved in epithelium homeostasis. PLoS One 3:e3518.

Kedinger V and Rio MC. 2007. TRAF4, the unique family member. Adv. Exp. Med. Biol. 597:60-71.

Kidder GM and McLachlin JR. 1985. Timing of transcription and protein synthesis underlying morphogenesis in preimplantation mouse embryos. Dev. Biol. 112:265-275.

Kwon J, Jeong SM, Choi I, Kim NH. 2016a. ADAM10 is involved in cell junction assembly in early porcine embryo development. PLoS One 11:e0152921.

Kwon J, Kim NH, Choi I. 2016b. ROCK activity regulates functional tight junction assembly during blastocyst formation in porcine parthenogenetic embryos. PeerJ 4:e1914.

Kwon J, Park S, Seong MJ, Choi I, Kim NH. 2019. Cytoplasmic polyadenylation element binding protein 2 (CPEB2) is required for tight-junction assembly for establishment of porcine trophectoderm epithelium. Reprod. Fertil. Dev. 31:412419.

Kwon JW, Kim NH, Choi I. 2016c. CXADR is required for AJ and $\mathrm{TJ}$ assembly during porcine blastocyst formation. Reproduction 151:297-304.

Muñoz-Espín D, Cañamero M, Maraver A, Gómez-López G, Contreras J, Murillo-Cuesta S, Rodríguez-Baeza A, VarelaNieto I, Ruberte J, Collado M, Serrano M. 2013. Programmed cell senescence during mammalian embryonic development. Cell 155:1104-1118.

Ock SA, Knott JG, Choi I. 2020. Involvement of CDKN1A (p21) in cellular senescence in response to heat and irradiation stress during preimplantation development. Cell Stress Chaperones 25:503-508.

Park YJ and Kim B. 2019. The expression and localization of ZO1 , claudin 1 , and claudin 4 in the pig epididymis. J. Anim. Reprod. Biotechnol. 34:190-196.

Régnier CH, Masson R, Kedinger V, Textoris J, Stoll I, Chenard MP, Dierich A, Tomasetto C, Rio MC. 2002. Impaired neural tube closure, axial skeleton malformations, and tracheal ring disruption in TRAF4-deficient mice. Proc. Natl. Acad. Sci. U. S. A. 99:5585-5590.

Régnier CH, Tomasetto C, Moog-Lutz C, Chenard MP, Wendling C, Basset P, Rio MC. 1995. Presence of a new conserved domain in CART1, a novel member of the tumor necrosis factor receptor-associated protein family, which is expressed in breast carcinoma. J. Biol. Chem. 270:25715-25721.

Rousseau A, Rio MC, Alpy F. 2011. TRAF4, at the crossroad between morphogenesis and cancer. Cancers (Basel) 3:27342749.

Rozan LM and El-Deiry WS. 2006. Identification and characterization of proteins interacting with Traf4, an enigmatic p53 target. Cancer Biol. Ther. 5:1228-1235.

Tesarík J. 1988. Developmental control of human preimplantation embryos: a comparative approach. J. In Vitro Fert. Embryo Transf. 5:347-362. 
Watson AJ and Barcroft LC. 2001. Regulation of blastocyst formation. Front. Biosci. 6:D708-D730.

Xu YC, Wu RF, Gu Y, Yang YS, Yang MC, Nwariaku FE, Terada LS. 2002. Involvement of TRAF4 in oxidative activation of c-
Jun N-terminal kinase. J. Biol. Chem. 277:28051-28057.

Zhou D, Niu Y, Cui XS. 2020. M-RAS regulate CDH1 function in blastomere compaction during porcine embryonic development. J. Anim. Reprod. Biotechnol. 35:12-20. 